\title{
DOS LECCIONES APRENDIDAS DE OPERACIONES MILITARES Y SU APORTE A LA FORMACIÓN DE OFICIALES
}

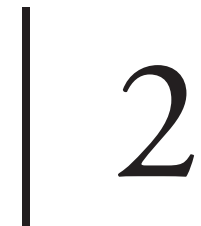

\author{
Erika Constanza Figueroa Pedreros ${ }^{1}$ \\ Yulieth Stefany Guancha Sánchez ${ }^{2}$
}

\section{Resumen}

Este documento recopila el aporte de las lecciones aprendidas producto de dos de las operaciones militares más importantes realizadas por unidades militares de gran experiencia en combate -en el contexto del conflicto armado-, para la formación e instrucción de los oficiales del Ejército Nacional. Tanto la operación Colombia realizada en el año de 1990 como la operación Independencia en el año de 1999, fueron decisivas para comprender la dinámica y transformación de las unidades militares y con ello, el proceso educativo que recibían los cadetes y alféreces de la Escuela Militar. Este capítulo responde al planteamiento formulado entre la educación militar y la historia institucional, evidenciada en el componente operacional, el cual proyecta la comprensión del ser militar, la adopción de estrategias y tácticas para el cumplimiento de la misión constitucional. De igual forma, ese aprendizaje también pretende aportar elementos importantes para evitar problemas legales a los integrantes de la fuerza.

Palabras Clave: lección aprendida, operación militar, formación académica y militar.

\section{Abstract}

This document compiles the contribution of the lessons learned as a result of two of the most important military operations carried out by military units with great experience in combat -in the context of the armed conflict-, for the training and instruction of the officers of the National Army. Both the Colombia operation carried out in 1990

1 Historiadora y Máster en Historia de las independencias de Iberoamérica. Docente e investigadora de la Facultad de Ciencias Militares de la Escuela Militar de Cadetes “General José María Córdova”. Contacto: ercofipe25@gmail.com

2 Trabajo de grado titulado: Construcción de lecciones aprendidas de las operaciones Colombia e Independencia del Batallón de Fuerzas Especiales No2 Francisco Vicente Almeyda Ballén. Escuela Militar de Cadetes “General José María Córdova”. Bogotá: Escuela Militar de Cadetes, 2017. 
and the Operation Independencia in 1999 were decisive in understanding the dynamics and transformation of the military units and, with it, the educational process that the cadets and alféreces of the Military School received. This chapter responds to the approach formulated between military education and institutional history, evidenced in the operational component, which projects the understanding of the military being, the adoption of strategies and tactics for the fulfillment of the constitutional mission. Similarly, this learning also aims to provide important elements to avoid legal problems to the members of the force.

Keywords: lesson learned, military operation, academic and military training.

\section{Introducción}

En el primer capítulo de esta obra se hizo hincapié en la formación militar a partir de la influencia ejercida por las diferentes sedes de la Escuela Militar del siglo XX, en especial por la última en el año 1940. La sede Rionegro y sus cambios arquitectónicos fueron determinantes en el proceso de instrucción militar y formación académica para quienes decidieron y deciden iniciar la carrera de las armas. Ahora vale la pena complementar, en qué sentido esa historia de la planta física de la puede ayudar a comprender no sólo la formación de los futuros oficiales, sino la forma en que se han adelantado las operaciones militares recientes y con ello establecer el tipo de aprendizajes dentro del contexto formativo militar generado a partir de las lecciones aprendidas.

En el marco del desarrollo de las operaciones militares del Ejército Nacional durante la segunda mitad del siglo XX, es posible evidenciar la trascendencia e impacto causado por las acciones de las unidades militares que controlaron y aún controlan la soberanía y defensa del territorio colombiano. Algunas de esas unidades militares se destacan por los excelentes resultados operacionales, que independiente a las circunstancias positivas o negativas fueron decisivas a la hora de cumplir con la misión constitucional de la Fuerza. (Guancha Sánchez, 2017)

Es esta una de las razones que justifican la elección del tema, construir historia operacional militar ${ }^{3}$ tomando como base el estudio de dos operaciones militares en relación a sus lecciones aprendidas desarrolladas por los hombres del Batallón de Fuerzas Especiales No2, en el marco del contexto del conflicto armado colombiano. De

3 Es aquella que estudia el arte de la guerra a través de las batallas y los combates analizando la estrategia y la táctica de los bandos en conflicto, observando la implementación de su doctrina, el uso de su logística, la utilización de su personal, el liderazgo de sus comandantes y la aplicación de los principios de la guerra, esto con el fin de sustraer lecciones del pasado que permitan establecer postulados teóricos en la ciencia militar del presente. Tomado del Centro de Estudios Históricos del Ejército de Colombia. Abril, 2018. 
igual manera, la elección de este tema responde a la necesidad de los militares colombianos por conocer y analizar aspectos operacionales que hacen parte de la historia del conflicto armado interno del siglo XX. (Guancha Sánchez, 2017)

Con base en esta información, este segundo capítulo al igual que el primero, intenta responder la siguiente pregunta de investigación: ¿Qué aprendizajes para la formación militar se pueden generar a partir de las lecciones aprendidas, producto de las operaciones militares comandadas por los oficiales del Ejército Nacional en el contexto del conflicto armado colombiano? Sin duda alguna, este cuestionamiento hace parte de la gran cantidad de preguntas sin resolver en el marco de la historia militar colombiana. No obstante, la pretensión es bastante ambiciosa, en primer lugar reconocer la existencia de una relación entre la formación militar que se vive en la Escuela Militar y las lecciones aprendidas, resultado del desarrollo de las operaciones militares planeadas por el cuerpo de oficiales. En segunda instancia, identificar ese tipo de procesos de enseñanza-aprendizaje entre la formación militar-académica y las lecciones aprendidas.

En este capítulo se ha establecido un argumento central que conlleva a dar respuesta a los interrogantes investigativos donde existiría una relación directa y de "larga duración" entre Educación Militar y su historia institucional y operacional como herramienta para adoptar a la formación de oficiales de la fuerza militar y comprender su influencia en la adopción de estrategias o la implementación de tácticas en operaciones militares recientes. Además, el conocimiento de todo lo anterior ayudaría a prevenir, fruto de las lecciones aprendidas, condenas a miembros del ejército.

\section{Las lecciones aprendidas de las operaciones militares como problemática en la investigación en las ciencias militares}

Dentro del desarrollo del trabajo de grado (documento base para escribir este documento) y propiamente de este capítulo, la información que relaciona las lecciones aprendidas con su importancia, significado, desarrollo histórico por no decir nula es muy escasa. No obstante, algunos autores mencionan que gracias a la existencia entre las ciencias militares y el arte de la guerra, en el sentido de comprender el conocimiento de la primera para explicar las causas, evolución y efectos de la segunda, "se indica que los principios de la guerra representan la concentración de experiencias acumuladas en un área de una ciencia o arte, obtenidas mediante el método científico de investigación para problemas de tipo teórico.” (Ortega Prado, 2010, pág. 12) Ahora bien, si la experiencia acumulada es elemento esencial para comprender las ciencias militares, las lecciones aprendidas cobran una importancia categórica dentro del escenario de la 
guerra, tanto así que hoy en día son materia de análisis dentro de los ejércitos, para ser objeto de investigación, precisamente por el aporte dado en el contexto bélico.

En el Ejército Nacional de Colombia, las lecciones aprendidas empezaron a ser estudiadas a profundidad en la primera década del siglo XXI. Gracias a la creación de la Dirección de Lecciones Aprendidas del Ejército DILEA -estructura que depende del Comando de Educación y Doctrina- la fuerza puede "direccionar y analizar esas lecciones observadas (positivas o negativas) basadas en la información obtenida durante una actividad administrativa, de instrucción, de entrenamiento u operaciones, con el fin de incidir en la generación o actualización de la doctrina." (Comando de Educación y Doctrina, 2016).

En la actualidad, la DILEA permite comprender más a fondo la importancia de las lecciones aprendidas en un escenario de combate, sin embargo, resulta interesante tener en cuenta el momento histórico en el que se desarrollaron las dos operaciones militares, objeto de investigación de este documento, pues cabe señalar, en dichos años no existía un sistema que albergara la información recopilada por quienes ejecutaban el cumplimiento de la misión operacional, como el caso de la operación Colombia e Independencia, ocurridas en la década de los años noventa del siglo XX. (Ejército Nacional, 2017).

\section{Las lecciones aprendidas en el Ejército Nacional: un análisis conceptual}

Las lecciones aprendidas en el Ejército Nacional son "el conocimiento obtenido y validado, el cual se deriva de la implementación de las propuestas de solución a las problemáticas identificadas, y el aprovechamiento de los aciertos obtenidos de las experiencias, generando un cambio en el comportamiento del personal de la Fuerza, impactando la doctrina, organización, material y equipo, personal, infraestructura, liderazgo, educación y mantenimiento" (DOMPILEM) (Ejército Nacional de Colombia , 2011, pág. 5).

La definición anterior hace parte del sistema de lecciones aprendidas para posicionar a la Fuerza como una organización de aprendizaje, debido a la necesidad que tuvo la institución militar en relación con su transformación doctrinal, en respuesta tanto a los requerimientos que tenía el Ministerio de Defensa Nacional como a los cambios del conflicto armado colombiano y el proceso de paz iniciado con el grupo armado ilegal FARC-EP.

Complementando el concepto de lecciones aprendidas, el Ejército Nacional creó un sistema que pudiera unificar todos los elementos de manera integrada, con el fin 
de facilitar la gestión de experiencias resultado de las operaciones militares en cumplimiento de la misión institucional, y garantizar el aprendizaje organizacional para el mejor desempeño de la Fuerza. De igual manera, fue necesario consolidar la información resultado de mesas de trabajo para lograr construir un proceso de lecciones aprendidas, fundamentado en una "secuencia lógica y ordenada de etapas, que se realizan para gestionar adecuadamente las experiencias derivadas de las operaciones, el entrenamiento militar y las actividades administrativas derivadas de las anteriores, para transformarlas en soluciones que contribuyan a la actualización o generación de la doctrina y mejoras del equipamiento.” (www.ejercito.mil.co, 2011, pág. 4).

Conceptualizar las lecciones aprendidas tuvo lugar después del año 2009, fue gracias a la disposición No 0030 del 26 de agosto en que fueron creadas y activadas diferentes direcciones de la antigua Jefatura de Educación y Doctrina, - hoy en día Comando de Educación y Doctrina- entre las cuales estuvo la Dirección de Doctrina y en cuya estructura contaba la sección de lecciones aprendidas. (Ejército Nacional, 2017, pág. 3)

En la doctrina OTAN se establece que el propósito del procedimiento de lecciones aprendidas es aprender eficientemente de la experiencia y proporcionar justificaciones validadas para enmendar la manera actual de hacer las cosas y mejorar el rendimiento, tanto durante el desarrollo de una operación. Para esto es necesario que sean sometidas a medidas de consideración. También requiere de la cadena de mando, tener un claro conocimiento sobre como priorizar las lecciones y como ponerlas en práctica. (Colom Piella, 2012)

\section{Propuesta metodológica para la construcción de las lecciones aprendidas de una operación militar}

Martha Arana en el libro Cultura de la investigación y gestión educativa expone la necesidad de trabajar de manera conjunta entre las diferentes áreas de las ciencias humanas, a partir de métodos aplicados a las ciencias militares, en especial a trabajos de grado encaminados a profundizar en el conocimiento investigativo y en la formación tanto de docentes como de estudiantes. (Cultura del a investigación y gestión educativa , 2016, pág. 19).

Partiendo desde este análisis, la metodología en los trabajos de grados de la Facultad de Ciencias Militares cumple un papel primordial, porque entrelaza esa cultura de la investigación con el producto final esperado por el estudiante y el tutor. La propuesta metodológica para el trabajo de grado -insumo de este capítulo- es la 
orientación dada según la guía de trabajos de grado de la Escuela Militar de Cadetes, fuente de gran ayuda para abordar el marco metodológico en trabajos dirigidos hacia las Ciencias Militares. (Guía para la elaboración del trabajo de grado, 2016, pág. 14).

Basado en el enfoque por competencias, el paradigma de la investigación es empírica analítica, "en el sentido de construir una herramienta de aprendiza militar, que, si bien es definida en los actuales manuales de doctrina y en el sistema de lecciones aprendidas, no fue construida para la época. Ahora, de igual forma responde a una investigación histórica - hermenéutica, por tratar la historia militar, y en especial por la búsqueda de fuente primaria que condujera el trabajo a la interpretación analítica”. (Guancha Sánchez, 2017, pág. 13) El enfoque es cualitativo, de tendencia analítica, para trabajar de la mano con el paradigma de la investigación; el nivel está encauzado al corte descriptivo, no obstante vale la pena señalar la relación dialéctica entre el análisis de la fuente encontrada con la descripción de los acontecimientos históricos, que permitieron la construcción de las lecciones aprendidas de una operación militar.

\section{Construcción de las lecciones aprendidas de las operaciones militares Colombia e Independencia del BFER2 como proceso educativo en la formación de los futuros oficiales del Ejército Nacional}

Hoy en día, el proceso de construcción de lecciones aprendidas es producto de un gran número de acciones realizadas por quienes planean y ejecutan una operación militar, debe contribuir a la actualización de la doctrina y a promover la cultura de mejoramiento del desempeño de las unidades, mediante de la Revista después de la Acción (RDA) (Ejército Nacional, 2017).

Ahora bien, para comprender la importancia de las lecciones aprendidas en el contexto educativo de la formación de los oficiales del ejército, cabe señalar el momento histórico vivido en la última década del siglo XX en Colombia y con él, las operaciones militares que evidenciaron cambios en el desarrollo del conflicto armado. Si bien, desde la VII conferencia de las FARC- EP en el año de 1982, aumentó el accionar delictivo del grupo guerrillero, con el fin de consolidar la toma del poder a través de la guerra (Centro Nacional de Memoria Histórica, 2014, pág. 110), fue hasta la década de los años noventa, en que las Fuerzas Militares y en especial el ejército, reorientaron sus esfuerzos para neutralizar las actividades delincuenciales del grupo guerrillero y mediante un planteamiento desarrollado en la Escuela Superior de Guerra, se dio inicio a una estrategia integral. (Santos Pico, 2007) 


\section{Operación Colombia e Independencia.}

Tomando en cuenta la descripción realizada por el Centro de Estudios Históricos del Ejército en relación a la operación Colombia ejecutada en diciembre del año 1990, se afirma que: (Históricas operaciones militares, 2014, pág. 67)

[E]sta operación hizo parte del Plan Tricolor de 1990, en él, las fuerzas del Estado estaban integradas por un grupo de tropas de asalto, un grupo de apoyo y un tercer grupo de cierre y bloqueo. El primer grupo lo integraban los Batallones de Fuerzas Especiales No 1 y 2 y de contraguerrillas 7 y 12, con un efectivo aproximado de 1300 hombres.

El segundo grupo lo integraban una batería de $120 \mathrm{~mm}$, el Grupo Marte antiexplosivos y el Batallón de Servicios No7. En el tercer grupo de cierre y bloqueo participaron los Batallones de Contraguerrillas No9y 13, los Batallones de Infantería No16, 21 y 27, el Batallón de Infantería 29 Rifles con la Compañía A en el sector de Villarrica y el Batallón Escuela de Artillería bloqueaba el sector desde Pasca hasta San Juan de Sumapaz.

La Fuerza de Tarea tenía un componente aéreo con un grupo de apoyo aero-táctico, un grupo de apoyo de fuego y un grupo de transporte. El concepto de la operación consistió en asaltos helicoportados con apoyo de fuego de ablandamiento y aero-tácticos sobre el objetivo Bravo con el Batallón de Fuerzas Especiales 1; objetivo Centauro con el Batallón Contraguerrilla No 7 y el objetivo Espuela con el Batallón de Fuerzas Especiales No2. Actuaba como reserva el Batallón de Contraguerrilla No12

Unos años después, del 12 al 14 de julio de 1999, tuvo lugar la operación militar Independencia, desarrollada dentro del programa "Cambio para construir la Paz", una política de Estado de quien era el presidente del país. En ella se pudo "bloquear y neutralizar las intenciones de las FARC-EP de cumplir con su última fase de guerra de guerrillas, pensada en la toma del poder a través de las armas". (Centro de Estudios Históricos del Ejército. División de Infantería “Gr José María Córdova”, 2014, pág. 90) Precisamente, en la fuente periodística de la época, el Tiempo relataba que "en plena arremetida guerrillera desplegada para fortalecer su posición cuando se aproximaba la instalación de la mesa de negociación entre ese grupo subversivo y el gobierno nacional, los aviones de combate AC 47 y los helicópteros artillados de la Fuerza Aérea, el Ejército y la Policía les propinaron a las FARC uno de los golpes más certeros, con un saldo de 202 guerrilleros muertos" (1999). 


\section{Las lecciones aprendidas de las operaciones militares Colombia e Independencia.}

A partir del sistema de lecciones aprendidas y la normatividad expedida por la Dirección de Doctrina del Ejército, se realizó la construcción del documento Revista Después de la Acción (RDA), con base en entrevistas realizadas a personal militar que participó en dichas operaciones militares, sumado a la información consignada en una cartilla de carácter simple ${ }^{4}$, que contiene registros históricos relacionados con el Batallón de Fuerzas Especiales No2 Francisco Vicente Almeyda Ballén.

Teniendo en cuenta la estructura de la $\mathrm{RDA}$, fueron evaluados los siguientes aspectos en las dos operaciones estudiadas: intención del comandante de escalones superiores, misión de la unidad táctica ${ }^{5}$, intención del comandante de la unidad táctica, ¿qué pasó?, ¿qué no pasó?, evaluación unidad táctica, evaluación en un escalón superior y recomendaciones para el entrenamiento. (Guancha Sánchez, 2017).

El primer aspecto, la intención del comandante en escala superior conlleva a determinar el propósito, las tareas claves y el estado final deseado de la operación militar, precisamente, esa organización permite comprender tres aspectos claves en cualquier misión operacional: clarificar el objetivo, determinar las tareas para el cumplimiento del objetivo y exponer los resultados después de realizada la operación; en este caso, el propósito en la Operación Colombia consistió en: neutralizar un blanco de alto valor, efectuar una operación ofensiva y ataque de tipo acción ofensiva, capturar o neutralizar a los miembros del secretariado del grupo guerrillero FARC-EP. Las tareas claves fueron: neutralizar el secretariado de las FARC, ubicar y bloquear los corredores de movilidad, identificar la localización exacta del objetivo, asignar responsabilidades a las unidades militares participantes y efectuar maniobras de golpes de mano. El estado final deseado reportó la neutralización en un 80\% del enemigo. (Guancha Sánchez, 2017)

En relación con la evaluación del comandante en escala superior la construcción de la lección aprendida arrojó la siguiente información:

4 Realizada por el Sargento Mayor Luis Enrique Viatela Cuello, quien fue orgánico del Batallón de Fuerzas Especiales No 2. El señor suboficial tuvo la oportunidad de recopilar la información consignada en el archivo operacional de la unidad militar y crear una cartilla con datos históricos relevantes, por tanto, ese documento sirvió como punto de partida para la búsqueda de información del proyecto y con ello, complementar la construcción de las lecciones aprendidas.

5 En la estructura del ejército, unidad táctica corresponde a un batallón y las órdenes son emitidas por el Comandante de Batallón. 
Tabla 1. Evaluación Comandante Escala Superior (un escalón arriba)

\section{Evaluación comandante escala superior \\ (Un escalón arriba)}

\begin{tabular}{ll}
\hline \multicolumn{1}{c}{ Aspectos por mejorar } & \multicolumn{1}{c}{ Aspectos por mantener } \\
\hline $\begin{array}{l}\text { Planeamiento de la operación, conocimiento del } \\
\text { enemigo }\end{array}$ & $\begin{array}{l}\text { El éxito de la operación se garantizó por el trabajo } \\
\text { conjunto con la Fuerza Aérea Colombiana, quien } \\
\text { mediante el apoyo de fuego directo dio avance a }\end{array}$ \\
\hline Conocimiento del área de operaciones & $\begin{array}{l}\text { las tropas en tierra, las cuales se movilizaron hacia } \\
\text { el objetivo }\end{array}$ \\
\hline $\begin{array}{l}\text { Comunicación con la tropa } \\
\begin{array}{ll}\text { Conocimiento del orden de batalla a todas las } \\
\text { unidades }\end{array}\end{array}$ \\
\hline
\end{tabular}

Fuente: Tomada de Guancha Sánchez, 2017

Tabla 2. Evaluación comandante escala superior (dos escalones arriba)

\begin{tabular}{l|l}
\hline \multicolumn{2}{c}{$\begin{array}{c}\text { Evaluación comandante escala superior } \\
\text { (Dos escalones arriba) }\end{array}$} \\
\hline \multicolumn{1}{c}{ Aspectos por mejorar } & \multicolumn{1}{c}{ Aspectos por mantener } \\
\hline El secreto de la misión & $\begin{array}{l}\text { *La confianza en el entrenamiento, el material } \\
\text { y equipo con que se cuenta y lo fundamental: } \\
\text { el recurso humano. }\end{array}$ \\
\cline { 1 - 1 } & *Apoyo de intendencia y armamento por la \\
$\begin{array}{l}\text { Apoyos de fuego directo e indirecto en el campo } \\
\text { de combate }\end{array}$ & \\
\hline Inteligencia de combate & \\
\hline Procedimiento de comando &
\end{tabular}

Fuente: Tomada de: Guancha Sánchez, 2017

Las recomendaciones para el entrenamiento apuntaron a fortalecer aspectos operacionales, que, si bien fueron determinantes a la hora de realizarla, fue necesario hacer hincapié en algunos de los principios de la guerra, como la planeación y el secreto.

\section{Tabla 3.}

\begin{tabular}{|c|l|c|}
\hline Área & \multicolumn{1}{|c|}{ Descripción } & Nivel \\
\hline Táctica & $\begin{array}{l}\text { a. Mantener una actualización del armamento } \\
\text { b. Preparación de las armas de acompañamiento y apoyo } \\
\text { c. Mejorar técnicas de maniobra, procedimientos tácticas y empleo de la doctrina }\end{array}$ & Individual \\
\hline Técnica & $\begin{array}{l}\text { a. Mejorar el planeamiento en situación real, donde la inteligencia sea detallada. } \\
\text { b. Mantener el secreto de la operación hasta el fin }\end{array}$ & Colectivo \\
\hline Física & $\begin{array}{l}\text { a. La preparación técnica y táctica permitió la reacción de forma oportuna y el } \\
\text { entrenamiento dado a las unidades, lo cual ayudó al buen desempeńo físico } \\
\text { dentro de las maniobras adelantadas por el batallón y el avance realizado por } \\
\text { las tropas. }\end{array}$ & Especialistas \\
\hline
\end{tabular}

Fuente: Tomada de: Guancha Sánchez, 2017 
En el contexto de la operación militar denominada Independencia Puerto Rico y Puerto Lleras (Libertad), el propósito fue liberar las dos poblaciones en mención, ambas controladas por la guerrilla de las FARC-EP. Las tareas claves consistieron en: aislar y neutralizar los integrantes de las FARC-EP que controlaban dichos territorios, generar disciplina y seguridad táctica, bloquear las rutas de repliegue o escape de los guerrilleros, identificar la ubicación exacta del enemigo y realizar la acción sobre el objetivo. El estado final deseado estuvo encaminado a generar el mínimo porcentaje de muertes en combates de las propias tropas, para poder continuar con la operación a orden y con ello, neutralizar al enemigo en un 80\%. (Guancha Sánchez, 2017)

Tabla 4. Evaluación comandante escala superior(un escalón arriba)

\begin{tabular}{ll}
\hline \multicolumn{1}{c}{$\begin{array}{c}\text { Evaluación comandante escala superior } \\
\text { (Un escalón arriba) }\end{array}$} \\
\hline \multicolumn{1}{c}{ Aspectos por mejorar } & \multicolumn{1}{c}{ Aspectos por mantener } \\
\hline $\begin{array}{l}\text { A la Brigada de Fuerzas Especiales le faltaba } \\
\text { tener el cuarto batallón fortalecido con soldados } \\
\text { entrenados, con material y equipo óptimo y con } \\
\text { suficiente experiencia al nivel de los otros tres } \\
\text { batallones, para poder salir a apoyar en las opera- } \\
\text { ciones y lograr materializar una brigada fortale- } \\
\text { cida con sus 4 batallones. }\end{array}$ & $* \begin{array}{l}\text { La capacidad de fuego y el entrenamiento del } \\
\text { personal de soldados. }\end{array}$ \\
\hline
\end{tabular}

Fuente: Tomada de: Guancha Sánchez, 2017

Tabla 5. Evaluación comandante escala superior (Dos escalones arriba)

\begin{tabular}{ll}
\hline \multicolumn{1}{c}{$\begin{array}{c}\text { Evaluación comandante escala superior } \\
\text { (Dos escalones arriba) }\end{array}$} \\
\hline \multicolumn{1}{c}{ Aspectos por mejorar } & \multicolumn{1}{c}{ Aspectos por mantener } \\
\hline $\begin{array}{l}\text { La consecución de más aeronaves de transporte de } \\
\text { tropa. }\end{array}$ & $\begin{array}{l}\text { La convicción por las misiones que se cumplen es } \\
\text { fundamental para el éxito de cualquier operación. }\end{array}$ \\
$\begin{array}{l}\text { Más helicópteros arpía para ametrallamiento y } \\
\text { lanzamiento de cohetes, ya que para la fecha sólo confianza en el entrenamiento, el material y } \\
\text { se contaba con 04 de la Fuerza Aérea, consideradas } \\
\text { insuficiente para el momento y no suplía las nece- } \\
\text { sidades a nivel nacional para cobertura del déficit } \\
\text { orden público alterado que se estaba viviendo. }\end{array}$ \\
\hline
\end{tabular}

Fuente: Tomada de: Guancha Sánchez, 2017 
Tabla 6. Consideracion especiales: aspectos positivos

\section{Consideracion especiales: aspectos positivos}

Disciplina y entrenamiento del personal

La aplicación de los diferentes procedimientos, base de patrulla, cruce áreas de peligro y toma del objetivo

El poder de fuego de las armas de acompañamiento

El entrenamiento y profesionalismo demostrado por los enfermeros de combate de la unidad

El mando, control y comunicaciones fue esencial en el desarrollo del combate

Las maniobras realizadas por los batallones

El valor, coraje y serenidad demostrado por todo el personal durante el ataque del enemigo

Fuente: Tomada de: Guancha Sánchez, 2017

Tabla 7

\begin{tabular}{clc}
\hline Área & \multicolumn{1}{c}{ descripción } & Nivel \\
\hline Táctica & $\begin{array}{l}\text { a. Mantener una actualización del armamento } \\
\text { b. Preparación de las armas de acompañamiento y apoyo } \\
\text { c. Mejorar técnicas de maniobra, procedimientos tácticas y empleo de la } \\
\text { doctrina }\end{array}$ & Individual \\
Técnica & $\begin{array}{l}\text { a. Mejorar el planeamiento en situación real, donde la inteligencia sea deta- } \\
\text { llada. }\end{array}$ & Colectivo \\
& $\begin{array}{l}\text { b. Mantener el secreto de la operación hasta el fin } \\
\text { Física }\end{array}$ & $\begin{array}{l}\text { a. La preparación técnica y táctica permitió la reacción de forma oportuna } \\
\text { dentro de los dos poblados, viendo así las ventajas y desventajas que } \\
\text { tuvieron las propias tropas en el campo de combate con el enemigo y } \\
\text { volviendo favorables cada situación que se presentó. }\end{array}$ \\
\hline
\end{tabular}

Fuente: Tomada de: Guancha Sánchez, 2017

\section{Relación entre la formación militar y las lecciones aprendidas de las operaciones}

En el sentido académico de verificar la pregunta del capítulo: ¿qué aprendizajes para la formación militar se pueden generar a partir de las lecciones aprendidas, producto de las operaciones militares comandadas por los oficiales del Ejército Nacional en el contexto del conflicto armado colombiano? es posible encontrar respuesta en la relación entre la malla curricular de la Escuela Militar de Cadetes para la época y las materias o asignaturas que impactaron la formación militar en sí. Cabe recordar, la formación militar de los futuros oficiales del ejército nacional en la década de los años 
ochenta y noventa del siglo XX, estuvieron acordes con la necesidad de integrar en el estudiante un plan curricular militar y académico, ambos de acuerdo con el contexto del conflicto armado colombiano.

Desde 1985 hasta 1990, las signaturas militares tenían un enfoque orientado en la disciplina, comportamiento, competencia del mando, preparación física y táctica, como puede observarse en la siguiente tabla:

Tabla 8

\begin{tabular}{|c|c|c|c|c|c|}
\hline 1985 & 1986 & 1987 & 1988 & 1989 & 1990 \\
\hline $\begin{array}{l}\text { Disciplina y } \\
\text { comporta- } \\
\text { miento }\end{array}$ & $\begin{array}{c}\text { Disciplina y } \\
\text { comporta- } \\
\text { miento }\end{array}$ & $\begin{array}{c}\text { Disciplina y } \\
\text { comporta- } \\
\text { miento }\end{array}$ & $\begin{array}{l}\text { Disciplina y } \\
\text { comporta- } \\
\text { miento }\end{array}$ & $\begin{array}{c}\text { Disciplina y } \\
\text { comporta- } \\
\text { miento }\end{array}$ & $\begin{array}{l}\text { Disciplina y } \\
\text { comporta- } \\
\text { miento }\end{array}$ \\
\hline Espíritu militar & Espíritu militar & Espíritu militar & Espíritu militar & & \\
\hline $\begin{array}{l}\text { Preparación } \\
\quad \text { física }\end{array}$ & $\begin{array}{l}\text { Preparación } \\
\quad \text { física }\end{array}$ & $\begin{array}{l}\text { Preparación } \\
\quad \text { física }\end{array}$ & $\begin{array}{l}\text { Preparación } \\
\quad \text { física }\end{array}$ & Cultura física & Cultura física \\
\hline $\begin{array}{l}\text { Preparación } \\
\text { Táctica }\end{array}$ & $\begin{array}{l}\text { Preparación } \\
\text { Táctica }\end{array}$ & $\begin{array}{l}\text { Preparación } \\
\text { Táctica }\end{array}$ & $\begin{array}{l}\text { Preparación } \\
\text { Táctica }\end{array}$ & & \\
\hline $\begin{array}{l}\text { Entrenamiento } \\
\text { técnico }\end{array}$ & $\begin{array}{l}\text { Entrenamiento } \\
\text { Técnico }\end{array}$ & $\begin{array}{l}\text { Entrenamiento } \\
\text { Técnico }\end{array}$ & $\begin{array}{l}\text { Entrenamiento } \\
\text { Técnico }\end{array}$ & $\begin{array}{l}\text { Preparación } \\
\text { técnica }\end{array}$ & $\begin{array}{l}\text { Preparación } \\
\text { técnica }\end{array}$ \\
\hline Organización y & Organización y & Organización y & Organización y & & \\
\hline Administración & Administración & Administración & Administración & & \\
\hline $\begin{array}{l}\text { Competencia } \\
\text { del mando }\end{array}$ & & & & $\begin{array}{l}\text { Desempeño en } \\
\text { terreno }\end{array}$ & $\begin{array}{c}\text { Desempeńo en } \\
\text { terreno }\end{array}$ \\
\hline $\begin{array}{l}\text { Competencia } \\
\text { como Instructor }\end{array}$ & & & & $\begin{array}{c}\text { Desempeño en } \\
\text { campańa }\end{array}$ & $\begin{array}{c}\text { Desempeño en } \\
\text { campaña }\end{array}$ \\
\hline
\end{tabular}

Fuente: Registro y Control Académico Escuela Militar de Cadetes. Primero Militar. Archivo Vicerrectoría Académica

La asignatura Desempeño en Campaña fue y sigue siendo considerada una de las más importantes dentro de la formación militar para un oficial, no obstante Preparación Técnica y Preparación Táctica también están entre las materias que cumplieron parte de la función de estudiar las lecciones aprendidas dentro de su contenido temático. En los ejercicios realizados en Desempeño en Campaña se evidenciaron la práctica de la doctrina militar en el área de operaciones, para llevar a cabo el cumplimiento de la misión institucional, al igual que las lecciones aprendidas de las operaciones realizadas por unidades militares en años anteriores. 
En los años siguientes antes de la operación Independencia, el aprendizaje de las lecciones aprendidas se intensificó debido al aumento de la intensidad horaria en la asignatura Desempeño en Terreno y Desempeño en Campaña. Fue a partir del año 1991, en que los estudiantes fortalecieron el proceso educativo militar y académico con la puesta en marcha del estudio a profundidad de los manuales doctrinales para combatir las nuevas formas de lucha de los grupos guerrilleros, entre ellos el manual de patrullas dirigidas. (Fuerzas Militares de Colombia, 1990).

Con la entrada en vigencia de las carreras profesionales complementarias, la formación militar reorientó sus esfuerzos al proyecto educativo de fortalecer la educación impartida, a partir de herramientas académicas que adicionaran elementos de gran impacto para el oficial en su desempeño laboral. Es por ello que en el año de 1994, el horario académico se combinó entre materias militares y materias académicas de carreras profesionales reconocidas por el Ministerio de Educación.

Tabla 9

\begin{tabular}{|c|c|c|c|c|c|c|c|}
\hline $\begin{array}{c}1994 \\
\text { Estudios } \\
\text { Universitarios } \\
\text { I }\end{array}$ & $\begin{array}{c}1994 \\
\text { Estudios } \\
\text { Universitarios } \\
\text { II }\end{array}$ & $\begin{array}{c}1995 \\
\text { Estudios } \\
\text { Universitarios } \\
\text { I }\end{array}$ & $\begin{array}{c}1996 \\
\text { Estudios } \\
\text { Universitarios } \\
\text { I }\end{array}$ & $\begin{array}{c}1996 \\
\text { Ciencias } \\
\text { jurídicas I }\end{array}$ & $\begin{array}{c}1996 \\
\text { Administración } \\
\text { I }\end{array}$ & $\begin{array}{c}1996 \\
\text { Ingeniería } \\
\text { I }\end{array}$ & $\begin{array}{l}1997 \\
\text { Curso General }\end{array}$ \\
\hline \multirow[t]{2}{*}{$\begin{array}{l}\text { Disciplina } \\
\text { y comporta- } \\
\text { miento }\end{array}$} & $\begin{array}{l}\text { Disciplina } \\
\text { y comporta- } \\
\text { miento }\end{array}$ & $\begin{array}{l}\text { Disciplina } \\
\text { y comporta- } \\
\text { miento }\end{array}$ & $\begin{array}{l}\text { Disciplina } \\
\text { y otras }\end{array}$ & $\begin{array}{l}\text { Disciplina } \\
\text { y otras }\end{array}$ & $\begin{array}{l}\text { Disciplina } \\
\text { y otras }\end{array}$ & $\begin{array}{l}\text { Disciplina } \\
\text { y otras }\end{array}$ & $\begin{array}{l}\text { Disciplina } \\
\text { y otras }\end{array}$ \\
\hline & & & $\begin{array}{l}\text { Área sicológica } \\
\text { y moral }\end{array}$ & & & & $\begin{array}{l}\text { Preparación } \\
\text { sicológica } \\
\text { y moral }\end{array}$ \\
\hline \multirow[t]{2}{*}{ Cultura física I } & Cultura física II & Cultura física I & Área física & Área física & Área física & Área física & Preparación física \\
\hline & & & $\begin{array}{l}\text { Área táctica } \\
\text { operacional }\end{array}$ & $\begin{array}{l}\text { Área táctica } \\
\text { operacional }\end{array}$ & $\begin{array}{l}\text { Área táctica } \\
\text { operacional }\end{array}$ & $\begin{array}{l}\text { Área táctica } \\
\text { operacional }\end{array}$ & $\begin{array}{l}\text { Preparación táctica } \\
\text { operacional }\end{array}$ \\
\hline \multirow[t]{2}{*}{$\begin{array}{l}\text { Preparación } \\
\text { técnica I }\end{array}$} & $\begin{array}{l}\text { Preparación } \\
\text { técnica II }\end{array}$ & $\begin{array}{l}\text { Preparación } \\
\text { técnica I }\end{array}$ & Área técnica & Área técnica & Área técnica & Área técnica & $\begin{array}{l}\text { Preparación } \\
\text { técnica }\end{array}$ \\
\hline & & & $\begin{array}{l}\text { Área admi- } \\
\text { nistración y } \\
\text { logística }\end{array}$ & & & & $\begin{array}{l}\text { Preparación } \\
\text { administración } \\
\text { y logística }\end{array}$ \\
\hline $\begin{array}{l}\text { Desempeńo } \\
\text { en terreno I }\end{array}$ & $\begin{array}{l}\text { Desempeńo } \\
\text { en terreno II }\end{array}$ & $\begin{array}{l}\text { Desempeńo } \\
\text { en terreno I }\end{array}$ & & & & & \\
\hline $\begin{array}{l}\text { Desempeño } \\
\text { en campaña I }\end{array}$ & $\begin{array}{l}\text { Desempeño } \\
\text { en campaña II }\end{array}$ & $\begin{array}{l}\text { Desempeño } \\
\text { en campaña I }\end{array}$ & & & & & \\
\hline
\end{tabular}

Fuente: Registro y Control Académico Escuela Militar de Cadetes. Primero Militar. Archivo Vicerrectoría Académica

La tabla anterior permite observar que en los ańos 1994 y 1995 la asignatura Desempeño en Terreno y Desempeño en Campaña cumplen un papel determinante 
en la formación militar, no obstante, para el año 1997, se reorganiza la malla curricular y la preparación táctica y técnica son la punta de lanza para el estudio de la doctrina militar y con ella, las lecciones aprendidas de las operaciones militares.

\section{A manera de conclusión}

Los años que terminan el siglo XX y dan inicio al siglo XXI, encajan con el momento histórico de la realización de la operación militar Independencia (1999), por tanto resulta pertinente resaltar que la malla curricular de la formación militar y académica de los estudiantes de la Escuela Militar de Cadetes se encontraba en constante evolución, en cumplimiento a los parámetros establecidos por el Ministerio de Educación Nacional, no por ello, se dejó de lado el estudio de elementos categóricos para los futuros oficiales del ejército, entre ellos el estudio y análisis de las lecciones aprendidas de las operaciones militares más importantes del país.

Ahora bien, haciendo una retrospectiva de la hipótesis presentada en el capítulo existiría una relación directa y de "larga duración" entre Educación Militar y su historia institucional y operacional como herramienta para adoptar a la formación de oficiales de la fuerza militar y comprender su influencia en la adopción de estrategias o la implementación de tácticas en operaciones militares recientes, nos atrevemos a afirmar que si existe una relación directa, permanente y de larga duración entre el proyecto educativo institucional de la Escuela Militar de Cadetes con el contexto operacional del Ejército Colombiano, porque al profundizar los elementos que componen una operación militar y los resultados obtenidos de ella, es posible comprender el contexto local, regional y nacional, tanto así que el Ejército Nacional influyó e influye de manera constante en el acontecer del país, en su rol de institución del Estado, garante de la soberanía territorial.

\section{Bibliografía}

Arana, M., \& Ibarra, V. (2016). Cultura del a investigación y gestión educativa . Bogotá, Colombia: Escuela Militar de Cadetes .

Centro de Estudios Históricos del Ejército. División de Infantería “Gr José María Córdova”. (2014). Históricas operaciones militares.Bogotá, Colombia: Ejército Nacional.

Centro Nacional de Memoria Histórica. (2014). Guerrilla y población civil. Trayectoria de las FARC 1949-2013. Bogotá, Colombia: CNMH.

Colom Piella, G. (26 de marzo de 2012). Luces y sombras de la transformación militar aliada. Revista Universidad de la Rioja , 17. 
Ejército Nacional de Colombia . (26 de mayo de 2011). www.ejercito.mil.co. Recuperado el 20 de agosto de 2018, de Ejército Nacional - Procedimiento Lecciones Aprendidas: https://www.ejercito.mil.co/?idcategoria $=230553 \& \mathrm{pag}=4$

Ejército Nacional de Colombia. (17 de mayo de 2016). Comando de Educación y Doctrina. (E. N. Colombia, Productor) Recuperado el 20 de agosto de 2018, de CEDOC: https:/ejercito.mil. co/?idcategoria $=396213$

Ejército Nacional. (27 de noviembre de 2017). Lineamientos funcionales para el sistema de lecciones aprendidas del Ejército Nacional.Directiva Permanente , 56. Bogotá, Colombia: Ejército Nacional.

El Tiempo. (12 de julio de 1999). En 48 horas muertos 202 guerrilleros.

Escuela Militar de Cadetes “General José María Córdova”. (2016). Guía para la elaboración del trabajo de grado. Documento administrativo . Bogotá, Colombia: Escuela Militar de Cadetes.

Fuerzas Militares de Colombia. (1990). Manual para la preparación y conducción de ejercicios tácticas FFMM3-16. Bogotá, Colombia: Fuerzas Militares de Colombia.

Guancha Sánchez, Y. (2017). Construcción de lecciones aprendidas de las operaciones Colombia e Independencia del Batallón de Fuerzas Especiales No2 Francisco Vicente Almeyda Ballén. Escuela Militar de Cadetes “General José María Córdova”. Bogotá: Escuela Militar de Cadetes.

Ortega Prado, R. (2010). Ciencias Militares. Ciencia , Arte, Método, Estado Mayor. Santiago, Chile: Academia de Guerra. Jefatura de Estudio. Ejército de Chile.

Santos Pico, M. (2007). Historia Militar del Ejército de Colombia. Bogotá, Colombia: Centro de estudios históricos del Ejército. 
Esta página queda intencionalmente en blanco. 